\title{
An evaluation of hospital admission respiratory disease attributed to sulfur dioxide ambient concentration in Ahvaz from 2011 through 2013
}

\author{
Gholamreza Goudarzi $^{1,2}$ • Sahar Geravandi ${ }^{3,4}$ - Esmaeil Idani ${ }^{1,5}$. \\ Seyyed Ahmad Hosseini ${ }^{6}$ - Mohammad Mehdi Baneshi ${ }^{7}$ - Ahmad Reza Yari ${ }^{8}$. \\ Mehdi Vosoughi $^{2}$ - Sina Dobaradaran ${ }^{9,10}$ - Saeed Shirali ${ }^{11}$ • \\ Mohammad Bagherian Marzooni $^{12}$ - Ali Ghomeishi ${ }^{4,13}$ - Nadali Alavi ${ }^{14}$. \\ Seyedeh Shaghayegh Alavi ${ }^{15}$ - Mohammad Javad Mohammadi ${ }^{1,2,4,16}$
}

\begin{abstract}
There is no doubt that air pollutants have adverse impacts on human health. The main objective of this study was to evaluate hospital admission respiratory disease (HARD) attributed to sulfur dioxide levels in Ahvaz during three successive years. Data was taken from Iranian Environmental Protection Agency (EPA). The AirQ2,2,3 model is used to quantify the impact of $\mathrm{SO}_{2}$ on inhabitants of Ahvaz and in terms of hospital admission respiratory diseases. This is a kind of statistical model which is based on
\end{abstract}

Responsible editor: Philippe Garrigues

Mohammad Javad Mohammadi

javad.sam200@gmail.com; Mohamadi.m@ajums.ac.ir

1 Air Pollution and Respiratory Diseases Research Center, Ahvaz Jundishapur University of Medical Sciences, Ahvaz, Iran

2 Environmental Technologies Research Center, Ahvaz Jundishapur University of Medical Sciences, Ahvaz, Iran

3 Islamic Azad University, Tehran Medical Sciences Branch, Tehran, Iran

4 Razi Teaching Hospital, Clinical Research Development Center, Ahvaz Jundishapur University of Medical Sciences, Ahvaz, Iran

5 Department of Internal Medicine, Division of Pulmonology, Imam Khomeini Hospital, Ahvaz Jundishapur University of Medical Sciences, Ahvaz, Iran

6 Nutrition \& Metabolic Diseases Research Center, Ahvaz Jundishapur University of Medical Sciences, Ahvaz, Iran

7 Social Determinants of Health Research Center, Yasuj University of Medical Sciences, Yasuj, Iran

8 Research Center for Environmental Pollutants, Qom University of Medical Sciences, Qom, Iran some epidemiological indices such as relative risk, baseline incidence, and attributable proportion. Sampling was already performed for $24 \mathrm{~h}$ in four stations during 2011-2013. Four stations are good representative for residential, high traffic, industry, and background sites which cover the whole area of the Ahvaz city. Regarding to gravimetric scale, raw data of sulfur dioxide was processed using Excel software. Encoding, filtering, and processing were conducted to prepare input file for the Air $\mathrm{Q}_{2,2,3}$ model. After running model,

9 Department of Environmental Health Engineering, Faculty of Health, Bushehr University of Medical Sciences, Bushehr, Iran

10 The Persian Gulf Marine Biotechnology Research Center, The Persian Gulf Research Center, Bushehr University of Medical Sciences, Bushehr, Iran

11 Hyperlipidemia Research Center, Department of Laboratory Sciences School of Paramedical Sciences, Ahvaz Jundishapur University of Medical Sciences, Ahvaz, IR, Iran

12 Environmental Research Institute, Academic Center for Education, Culture and Research (ACECR), Rasht, Iran

13 Department of Anaesthesiology, Faculty of Medicine, Ahvaz Jundishapur University of Medical Sciences, Ahvaz, Iran

14 Occupational Hazards Control Research Center and Department of Environmental Health Engineering, School of Public Health Environmental, Shahid Beheshti University of Medical Sciences, Tehran, Iran

15 Faculty of Food Science \& Technology, Tehran University, Tehran, Iran

16 Student Research Committee, Department of Environmental Health Engineering, Ahvaz Jundishapur University of Medical Sciences, Ahvaz, Iran 
outputs presented in term of hospital admissions respiratory cases. Based on our result, the highest mean and maximum of seasonal and annual levels for sulfur dioxide were observed in 2013. We concluded that obnoxious quality of fuel and some deficiencies in maintenance and operation of industries lead to worse quality of ambient air especially in 2013. Cumulative cases of HARD attributed to sulfur dioxide level at central of relative risk (RR) were estimated 24,25 , and 30 persons for 2011, 2012, and 2013, respectively. The finding of this study showed that total mean of sulfur dioxide was higher than standard concentration. We also noticed that wintertime concentrations of sulfur dioxide during three successive years were higher than of those levels in summer.

Keywords Sulfur dioxide $\cdot$ Hospital admissions respiratory disease $\cdot$ Health $\cdot$ Ahvaz

\section{Introduction}

Seriousness of air pollution lies in the fact that high, potentially harmful pollutant levels are produced in environments which can be harmful for human health (Geravandi et al. 2016a; Goudarzi et al. 2015d; Taghavirad et al. 2014; Ghozikali et al. 2015b; Soleimani et al. 2016; Neisi et al. 2016; Naimabadi et al. 2016). The most important of air pollutants are particulate matter, ozone $\left(\mathrm{O}_{3}\right)$, nitrogen dioxide $\left(\mathrm{NO}_{2}\right)$, sulfur dioxide $\left(\mathrm{SO}_{2}\right)$, and carbon monoxide $(\mathrm{CO})$ (Peters et al. 2000; Wong et al. 2002; Zallaghi et al. 2015). The main sources of sulfur dioxide are volcanoes, various industrial processes, transportation, economic development, coal, petroleum, domestic fuel burning, and vehicles in megacities. Several studies show a connection between sulfur dioxide exposure and increased emergency departments visits and hospital admissions for respiratory illnesses. The exposure to sulfur dioxide is extremely risky for people's health because these compounds enter the repository system directly through the airways (Geravandi et al. 2015a; Katsouyanni et al. 1997).

Sulfur dioxide can be absorbed into your body through your nose and lungs. In recent years, several hundred epidemiological studies showed that increase in the air pollutant concentration can increase cases in hospital admission for pulmonary and cardiac disease (Hoek et al. 2013; Jane and Fanny 2015; Kariisa et al. 2015). The most important health effects of sulfur dioxide are classified into two classes; short-term effects are associated with maximum concentration of $\mathrm{SO}_{2}$ and long-term impacts which are related to average concentration of sulfur dioxide. Breathing difficulty; hospital admission rates increase in children, elderly, and asthmatics; pulmonary edema; eye irritation; coughing; asthma attacks; increased risk of respiratory disease and respiratory infections; reduced lung function; and cardiovascular disease are the most important symptoms of short- and long-term effects of sulfur dioxide (Lave and
Seskin 2013; Mraihi et al. 2015; Norval et al. 2011; PAGE 2003; Peng et al. 2015; Pope et al. 2002; Pride et al. 2015; Raaschou-Nielsen et al. 2013; Woerman 2013).

$\mathrm{Wu}$ et al. in their study had shown a relationship between long-term sulfur dioxide exposure and upper respiratory outpatients (Wu et al. 2015). In 2009, in Tabriz city, Iran Ghozikali et al. estimated the chronic obstructive pulmonary disease hospitalizations attributed to $\mathrm{SO}_{2}$ (Ghozikali et al. 2015a). In another study in Detroit, USA, Lipmann et al. reported meaningful association between sulfur dioxide level and health effects on human (Lippmann et al. 2000). An investigation in Quebec, Canada estimates the association between daily levels of sulfur dioxide and hospitalizations for respiratory problems (Labelle et al. 2015). In similar works, Geravandi et al. studied the association between hospital admissions respiratory disease attributed to the sulfur dioxide (Geravandi et al. 2015a; Goudarzi et al. 2014).

In the previous studies, we estimated the health endpoints related to $\mathrm{SO}_{2}$ or other pollutant just in 1 year, but we designed the present study to evaluate the health effects of $\mathrm{SO}_{2}$ during three successive years regarding to the hospital admission respiratory disease (HARD). Therefore, a descriptive statistics of sulfur dioxide concentration, its fluctuation, and different attributable proportion were also shown in this study. It is noteworthy that calculating the number of hospital-admitted individuals attributed to air pollutants in a well-known polluted city is very crucial for medical sciences university as an organization that is responsible for providing health in Khuzestan province especially Ahvaz.

\section{Material and methods}

The present study is an epidemiological study. From exposure to outcome is the sign of cohort study in epidemiological classification. Using the Air $\mathrm{Q}_{2,2,3}$ model and considering three successive years could be other differences with cohort studiers.

The HARD cases attributed to sulfur dioxide in Ahvaz city in 2011 through 2013 were calculated based on the utilizing relative risk and attributable proportion and baseline incidence from WHO data.

Sampling was already performed for $24 \mathrm{~h}$ at four stations by the Iranian Environmental Protection Agency (EPA). Stations were Naderi, Behdasht Ghadim, Havashenasi, and Mohitzist. Therefore, in the present study, $24 \times 4 \times 365 \times 3$ samples in ambient air of Ahvaz were taken. These raw data then were processed by Excel software using encode, moving average, filter, and other techniques. AirQ 2.2 .3 software was proved to be a valid and reliable tool to estimate and predicts the health endpoint of criteria pollutants. This model includes four screen inputs (Supplier, AQ data, Location, Parameter) and two output screens. 


\section{Geographical features of Ahvaz}

Ahvaz city, with a population of 1 million approximately, the capital of Khuzestan province is located between 48 to $49^{\circ}$ and $29 \mathrm{~min}$ of the eastern longitude in the Greenwich meridian and 30 to $32^{\circ}$ and $45 \mathrm{~min}$ of the northern latitude from the equator (Dobaradaran et al. 2016; Geravandi et al. 2015d; Goudarzi et al. 2015a; Zallaghi et al. 2014b).

Ahvaz is located in the dry area of Iran with an area of $140 \mathrm{~km}^{2}$ and its average yearly rainfall is about $213 \mathrm{~mm}$. To perform this study, data was taken from Iranian EPA. Location of the study area and sampling station in Ahvaz are presented in Fig. 1.

\section{Statistical model}

In the present study, we used statistical model based on epidemiological investigations to find relationship between sulfur dioxide concentrations and hospital admissions respiratory disease.

The impact of sulfur dioxide on the HARD can be assessed by calculating the attributable proportion (AP) (Mohammadi et al. 2015). The AP implies to that part of health effects which can be attributed to the sulfur dioxide exposure in Ahvaz population. Attributable proportion was multiplied at baseline incidence and divided to $10^{5}$ (Geravandi et al. 2016b; Zallaghi et al. 2014a). Obtained value should be multiplied at population $\left(10^{6}\right.$ as population of Ahvaz). We applied some coefficients as model parameters that attribute the HARD cases to be exposed to sulfur dioxide (Goudarzi et al. 2015b). In the parameter screen, we calculated attributable proportion regarding the concentration of pollutant, baseline incidence (BI), and relative risk (RR).

$\mathrm{BI}$ is defined as the event incidence in the population in its place as the baseline (Nelson et al. 2015). Term of AP in percentage was calculated as the following formula:

$\mathrm{AP}=\operatorname{SUM}\{[\operatorname{RR}(\mathrm{c})-1] \mathrm{p}(\mathrm{c})\} / \operatorname{SUM}[\operatorname{RR}(\mathrm{c}) \mathrm{p}(\mathrm{c})]$

Where $\mathrm{RR}(\mathrm{c})$ is the relative risk for category $\mathrm{c}$ of exposure and $\mathrm{p}(\mathrm{c})$ is the proportion of Ahvaz population in category $\mathrm{c}$ of exposure.

The relative risk is a measure of association between exposure to dangers agent and health endpoint (Geravandi et al. 2015b; Goudarzi et al. 2015c). Amount of RR was calculated using the following equation (Goudarzi et al. 2015b, 2015d; Mohammadi et al. 2015):

$\mathrm{RR}=$ Incidence in the exposed population/Incidence in the non exposed population

\section{Results}

Based on result of our study, the annual average sulfur dioxide concentrations increased from 2011 through 2013. Table 1 shows that annual average of sulfur dioxide concentration in Ahvaz which is higher than the national

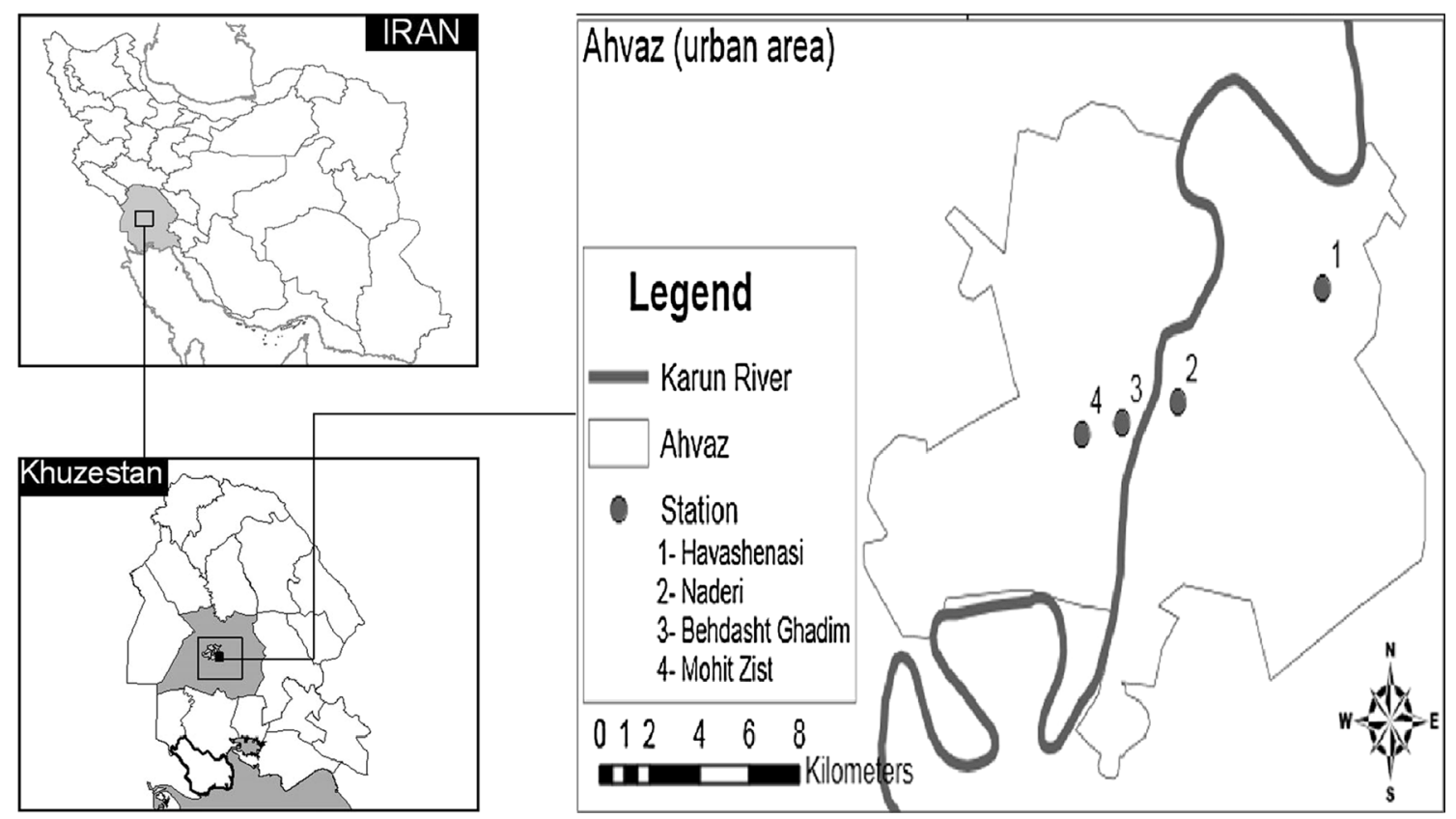

Fig. 1 Location of the study area and sampling station in the Khuzestan Province (Ahvaz city), in the south west of Iran 
ambient air quality standard (NAAQS). The primary and secondary standard of sulfur dioxide according to NAAQS are $75 \mathrm{ppb}(1 \mathrm{~h})$ and $0.5 \mathrm{ppm}(3 \mathrm{~h})$, respectively (Geravandi et al. 2015a).

The yearly mean, spring mean, summer mean, winter mean, autumn mean, the annual 98 percentile, summer maximum, and winter maximum of sulfur dioxide concentrations in these stations are presented in Table 1. Wintertime levels of $\mathrm{SO}_{2}$ during three successive years were higher than those concentrations in summer. As seen, the highest annual average, seasonal average, as well as the maximum of season occurred in 2013.

Number of HARD cases related to sulfur dioxide concentration is shown in Table 2. Estimated number of excess cases attributed to sulfur dioxide at central RR (1.01) during 2011 through 2013 was 24,25 , and 30, respectively. Term of BI implies to cumulative cases of outcome that happened in 100,000 of population. Central RR can be a good representative of real situation in view of sulfur dioxide health effects.

The HARD versus sulfur dioxide concentration during 2011 until 2013 is shown in Fig. 2. As seen, percentages of attributable proportions at central RR were 3.9, 4, and 5.63 during 2011, 2012, and 2013, respectively. It is apparent that $52 \%$ of excess cases associated with $\mathrm{SO}_{2}$ level occurred in days that concentration of sulfur dioxide not exceeding from $110 \mu \mathrm{g} / \mathrm{m}^{3}$ (Fig. 2). A linear trend was observed between $\mathrm{SO}_{2}$ levels and cumulative of hospital admissions respiratory cases. The more concentrations we had, the more hospital admitted individuals we observed. Smoothed line above $180 \mu \mathrm{g} / \mathrm{m}^{3}$ showed that there were no extra cases afterward. In the other hand, by an increase in $\mathrm{SO}_{2}$ level, the number of excess cases is incremented but increasing would be halted in a certain level of $\mathrm{SO}_{2}$ and then it would be shifted to a smoothed line (remain constant).

Table 1 Sulfur dioxide concentrations $\left(\mu \mathrm{g} \mathrm{m}^{-3}\right)$ in Ahvaz during 2011 to 2013

\begin{tabular}{llll}
\hline Parameters & \multicolumn{2}{l}{ Study years } & \\
\cline { 2 - 4 } & $\begin{array}{l}\text { Ahvaz city } \\
(2011)\end{array}$ & $\begin{array}{l}\text { Ahvaz city } \\
(2012)\end{array}$ & $\begin{array}{l}\text { Ahvaz city } \\
(2013)\end{array}$ \\
\hline Annual mean & $91 / 07$ & $92 / 75$ & $112 / 30$ \\
Spring mean & $30 / 18$ & 32 & $39 / 20$ \\
Summer mean & $53 / 12$ & 46 & 55 \\
Autumn mean & $108 / 65$ & 120 & 146 \\
Winter mean & $172 / 32$ & 173 & 209 \\
Annual 98 percentile & $192 / 71$ & 281 & $330 / 60$ \\
Summer maximum & 75 & $82 / 32$ & $100 / 79$ \\
Winter maximum & 242 & $267 / 10$ & 322 \\
\hline
\end{tabular}

Table 2 Estimation of relative risk, attributable proportions, and cases of people suffering from the HARD (baseline incidence $=1260$ per $10^{5}$ )

\begin{tabular}{llll}
\hline Estimate & \multicolumn{2}{l}{ Indicator } & \\
\cline { 2 - 4 } & $\begin{array}{l}\text { RR (Central), } \\
95 \% \text { CI }\end{array}$ & AP (\%) & $\begin{array}{l}\text { Attributable excess } \\
\text { cases (persons) }\end{array}$ \\
\hline Ahvaz city (2011) & $1.01(1.006-1.014)$ & 3.9261 & 24.6 \\
Ahvaz city (2012) & $1.01(1.006-1.014)$ & 4.0350 & 25.8 \\
Ahvaz city (2013) & $1.01(1.006-1.014)$ & 5.6354 & 30 \\
\hline
\end{tabular}

Figure 3 shows the relationship between the cumulative hospital admissions respiratory disease versus sulfur dioxide level during three successive years. Keep in mind that in 2011, $65 \%$ of this number has occurred in the days with concentrations lower than $140 \mu \mathrm{g} / \mathrm{m}^{3}$. It should be noted that $49 \%$ of these cases have occurred in days with $\mathrm{SO}_{2}$ levels not exceeding from $100 \mu \mathrm{g} / \mathrm{m}^{3}$.

\section{Discussion}

In recent decades, air pollution is considered as a major concern for nowadays communities. In this study, we estimated the effects of exposure to sulfur dioxide among citizens of Ahvaz. It should be noted that high density of industries (steel, oil, and gas) makes Ahvaz as one of the most important $\mathrm{SO}_{2}$ emitter (Geravandi et al. 2015c).

Based on the results of this study, an increase of $10 \mu \mathrm{g} /$ $\mathrm{m}^{3}$ in sulfur dioxide level was associated with an increase of $3.4 \%$ in the HARD. Ahvaz has been well known due to industries such as oil, petroleum, steel, gas, and power plants.

Sunyer et al. in their study had shown the association of daily sulfur dioxide air pollution levels with hospital admissions for cardiovascular diseases in Europe. They demonstrated that an increase of $10 \mu \mathrm{g} / \mathrm{m}^{3}$ in sulfur dioxide levels was related to an increase of $0.7 \%$ in hospital admissions for cardiovascular diseases (Sunyer et al. 2003).

As mentioned earlier, high percentage of the observed hospital admissions in our study was related to high concentration of measured sulfur dioxide in Ahvaz. In another study in Detroit, USA, Lipmann et al. reported a meaningful association between sulfur dioxide and health effects on human. It was observed that an increase of $10 \mu \mathrm{g} / \mathrm{m}^{3}$ in the sulfur dioxide was associated with an increase of $2 \%$ in hospital admissions (Lippmann et al. 2000).

High percentage of the HARD in Ahvaz can be related to existing heavy industry and high sulfur dioxide emitters particularly in wintertime. Previous study showed that an 
Fig. 2 Relationship between cumulative numbers of HARD versus sulfur dioxide concentration in Ahvaz, 2011-2013
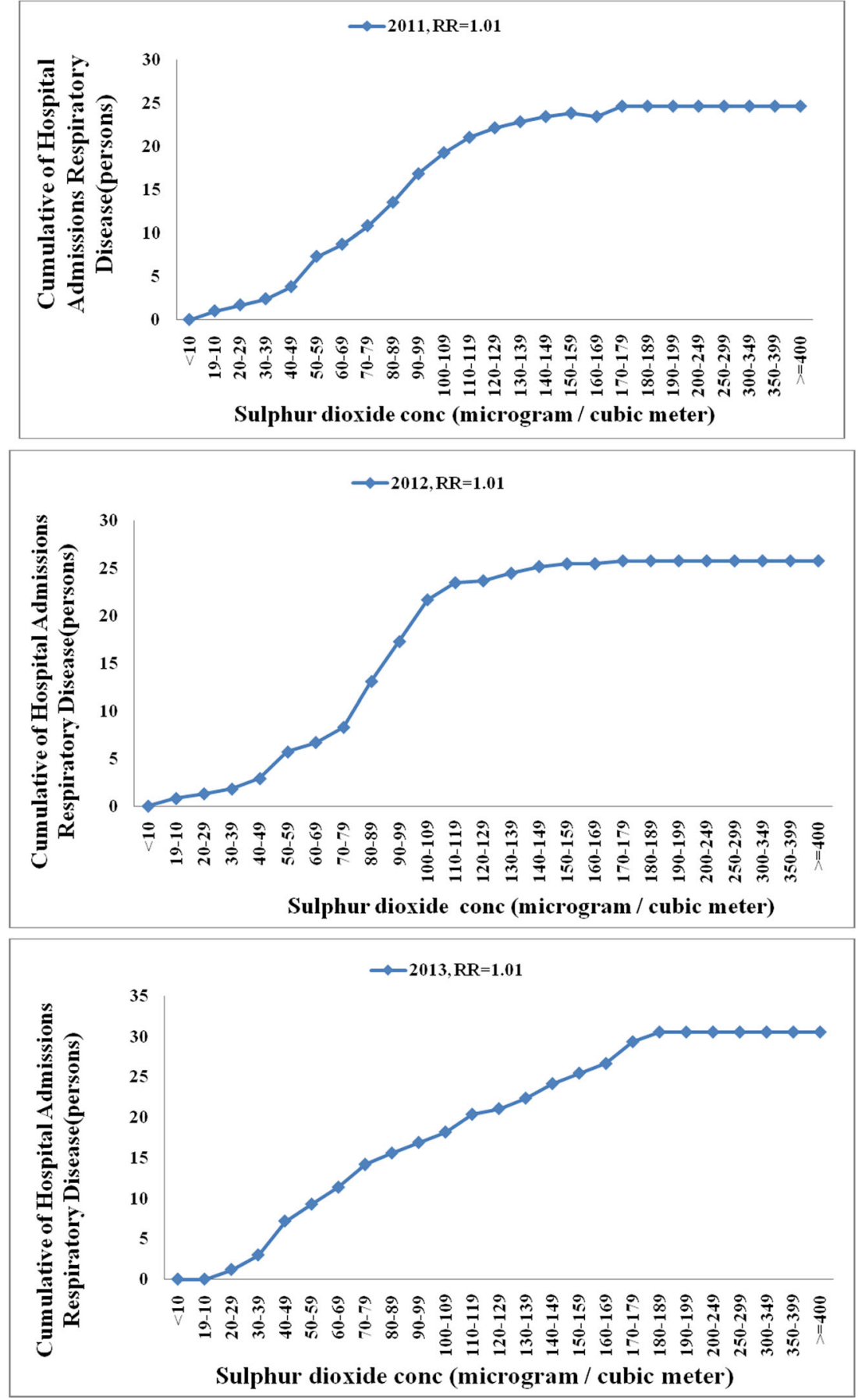

increase of $10 \mu \mathrm{g} / \mathrm{m}^{3}$ in $\mathrm{SO}_{2}$ was associated with an increase of $2.4 \%$ in hospital admissions respiratory cases in six Italian cities (Biggeri et al. 2001).

The results of this study showed that the concentration of sulfur dioxide in Ahvaz was higher than Italian cities. Based on the results of Jiangbei, Ningbo study, an increase of 10 to $18 \%$ in $\mathrm{SO}_{2}$ level was associated with an increase of 0.44 with the excessive risk in respiratory diseases ( $\mathrm{Wu}$ et al. 2015). It should be noted that changing stability condition from super adiabatic to sub adiabatic, decreasing maximum mixing heights, and more fuel consumption in cold season could be possible reasons for increasing sulfur dioxide levels in wintertime during this study.

Replacing gas fuel instead of petroleum residue (mazut) in industries during cold seasons particularly for power plants could be a reasonable strategy to diminish levels of sulfur dioxide in atmosphere of megacities like 


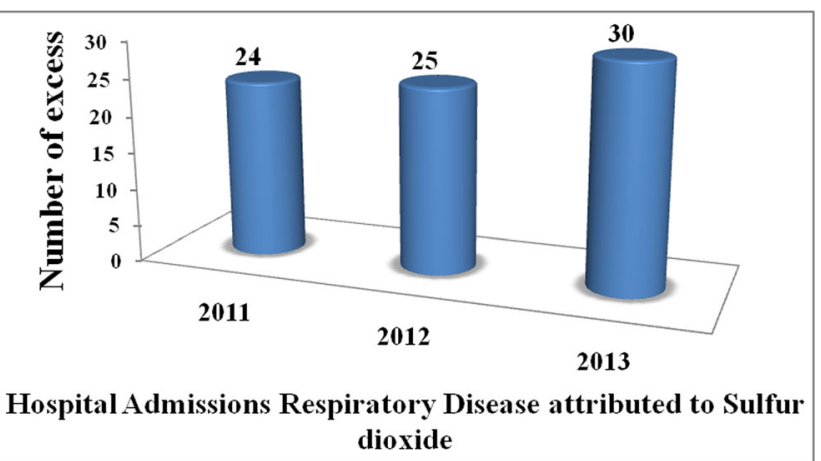

Fig. 3 Relationship between cumulative of HARD attributed to sulfur dioxide

Ahvaz. Using low sulfur gasoil $(S<50 \mathrm{ppm})$ in trucks and high-duty vehicles can be a feasible measure to in the ambient air of Ahvaz city. Model based works scientists try to simplify the reality. It is impossible to find a community to allow us to evaluate health outcomes when they are breathing a certain pollutant. So, the perfect health effect model such as AirQ $_{2,2,3}$ would allow us to predict health endpoints which are attributed to that certain pollutant for any specified meteorological conditions, at any location, for any time period, with the total confidence in our assessment. The knowledge about predicted number of cases for respiratory diseases can be helpful for authorities, health care centers, medical services, and decision makers in the field of urban air pollution.

Frankly speaking, in terms of limitations, there would be an old belief on using all kind of models from numerical to statistical, and it was written in "air pollution control engineering" book that "all models are wrong; some models are useful." It is because of this fact that models reflect a simulation of the mechanism or process which happened in reality. So, it is not reality, and it is a simplification of the fact to have a better understanding of the reality. We assumed that concentrations on these stations in some cases represent the exposure to all people living in the study areas. Also in Ahvaz which is affected by other pollutants as well as catastrophic phenomena such as Middle Eastern Dust (MED), events with the same RR as one applied in the normal days was used for quantification of the health impacts attributed to $\mathrm{SO}_{2}$.

It is obvious that people inhale a mixture of pollutants in megacities like Ahvaz.

Therefore, we estimated outcomes attributed to $\mathrm{SO}_{2}$ which may be underestimated or overestimated due to existing other pollutants into the air.

Future investigations in collaboration with international scientific teamwork are needed to explore more details for this kind of studies toward mitigating the impact of sulfur dioxide or other pollutants on inhabitant in megacities.

\section{Conclusion}

In megacities such as Ahvaz, the dilution capacity of atmosphere is limited due to emissions from industries, transportation systems, and adverse weather conditions. We concluded that obnoxious quality of fuel which was enrich in sulfur and benzene content led to worse quality of breathing air particularly in 2013. In our study, increasing the relative risk of HARD was a function of $\mathrm{SO}_{2}$ concentration, and we would expect to observe higher cases of HARD due to higher AP resulted from increased level of pollutant in 2013.

Careful monitoring, control of urban traffic, application of technical methods for decreasing sulfur dioxide entering to the atmosphere from sources such as oil and petrochemical industry, and strict regulations to develop green area will have an important role in controlling and decreasing sulfur dioxide.

We recommended to authorities in field of urban air quality to perform several feasible strategies toward producing low sulfur and benzene fuels, modern automobiles and trucks, as well as manipulating in industries processes, to reduce level of $\mathrm{SO}_{2}$ in ambient air.

Acknowledgment The authors would like to thank student Research committee, Ahvaz Jundishapur University of Medical Sciences for providing financial supported by grant $(95 \mathrm{~s} 16)$ of this research.

\section{Compliance with ethical standards}

Funding/support This work was financially supported by grant (95s16) from Vice-Chancellor for research Affairs of Ahvaz Jundishapur University of Medical Sciences.

\section{References}

Biggeri A, Bellini P, Terracini B, Italian MG (2001) Meta-analysis of the Italian studies on short-term effects of air pollution. Epidemiol Prev 25:1-71

Dobaradaran S, Geravandi S, Goudarzi G, Idani E, Salmanzadeh S, Soltani F et al. (2016) Determination of cardiovascular and respiratory diseases caused by PM10 exposure in Bushehr. J Mazandaran Univ Med Sci 26(139):42-52

Geravandi S, Goudarzi G, Mohammadi MJ, Taghavirad SS, Salmanzadeh S (2015a) Sulfur and nitrogen dioxide exposure and the incidence of health endpoints in Ahvaz, Iran. Health Scope 4(2):e24318

Geravandi S, Goudarzi G, Vosoughi M, Javad Mohammadi MJ, Salmanzadeh S, Zallaghi E (2015b) Relationship between particulate matter less than 10 microns exposures and health effects on humans in Ahvaz, Iran. Archives of Hygiene Sciences 4(2):23-32

Geravandi S, Goudarzi G, Vousoghi Niri M, Mohammadi MJ, Saeidimehr S, Geravandi S (2015c) Estimate of cardiovascular and respiratory mortality related to sulfur dioxide pollutant in Ahvaz. Journal of Environmental Studies 41(2):13-15

Geravandi S, Takdastan A, Zallaghi E, Niri MV, Mohammadi MJ, Saki H, Naiemabadi A (2015d) Noise pollution and health effects. Jundishapur Journal of Health Sciences 7(1):e25357 
Geravandi SGG, Yari AR, Idani E, Yousefi F, Soltani F et al. (2016a) An estimation of COPD cases and respiratory mortality related to ground-level ozone in the metropolitan Ahvaz during 2011. Archives of Hygiene Sciences 5(1):15-21

Geravandi S, Goudarzi G, Soltani F, Salmanzadeh S, Ghomeishi A, Zalaghi E et al. (2016b) The cardiovascular and respiratory deaths attributed to sulfur dioxide in Kermanshah. Journal of Kermanshah University of Medical Sciences 19(6):319-26

Ghozikali MG, Mosaferi M, Safari GH, Jaafari J (2015a) Effect of exposure to $\mathrm{O}_{3}, \mathrm{NO}_{2}$, and $\mathrm{SO}_{2}$ on chronic obstructive pulmonary disease hospitalizations in Tabriz, Iran. Environ Sci Pollut Res 22:2817-2823

Ghozikali MG, Borgini A, Tittarelli A, Amrane A, Naddafi K, Mohammadyan M et al. (2015b) Quantification of the health effects of exposure to air pollution (NO2) in Tabriz, Iran. Fresenius Environ Bull 24:4142-8

Goudarzi G, Geravandi S, Salmanzadeh S, Mohammadi MJ, Zallaghi E (2014) The number of myocardial infarction and cardiovascular death cases associated with sulfur dioxide exposure in Ahvaz, Iran. J Archives of Hygiene Sci 3(3):112-119

Goudarzi G, Geravandi S, Foruozandeh H, Babaei AA, Alavi N, Niri MV, et al. (2015a) Cardiovascular and respiratory mortality attributed to ground-level ozone in Ahvaz, Iran. Environ Monit Assess 187(8):1-9

Goudarzi G, Geravandi S, Mohammadi MJ, Salmanzadeh S, Vosoughi M, Sahebalzamani M (2015b) The relationship between air pollution exposure and chronic obstructive pulmonary disease in Ahvaz, Iran. Chronic Diseases Journal 3(1):14-20

Goudarzi G, Geravandi S, Saeidimehr S, Mohammadi MJ, Vosoughi M, Salmanzadeh S, et al. (2015c) Estimation of health effects for $\mathrm{PM}_{10}$ exposure using of air Q model in Ahvaz City during 2009. Iranian Journal of Health and Environment 8(1):117-126

Goudarzi GR, Geravandi S, Salmanzadeh S, Mohammadi MJ (2015d) An estimation of respiratory deaths and COPD related to $\mathrm{SO}_{2}$ pollutant in Tabriz, northwest of Iran (2011). Razi Journal of Medical Sciences 22(131):44-50

Hoek G, Krishnan RM, Beelen R, Peters A, Ostro B, Brunekreef B, Kaufman JD (2013) Long-term air pollution exposure and cardiorespiratory mortality: a review. Environ Health 12:43

Jane C, Fanny W (2015) Air pollution: its impact on adult patients with respiratory conditions. The Cover Shot 20:12

Kariisa M, Foraker R, Pennell M, Buckley T, Diaz P, Criner GJ, Wilkins J III (2015) Short-and long-term effects of ambient ozone and fine particulate matter on the respiratory health of chronic obstructive pulmonary disease subjects. Archives of environmental \& occupational health 70:56-62

Katsouyanni K et al. (1997) ) Short term effects of ambient sulphur dioxide and particulate matter on mortality in 12 European cities: results from time series data from the APHEA project. BMJ 314:1658

Labelle R, Brand A, Buteau S, Smargiassi A (2015) Hospitalizations for respiratory problems and exposure to industrial emissions in children. Environment and Pollution 4:77

Lave LB, Seskin EP (2013) Air pollution and human health. Routledge, London

Lippmann M, Ito K, Nadas A, Burnett RT (2000) Association of particulate matter components with daily mortality and morbidity in urban populations. Res Rep Health Eff Inst 95:5-72

Mohammadi MJ, Godini H, Khak MT, Daryanoosh SM, Dobaradaran S, Goudarzi G (2015) An association between air quality and COPD in Ahvaz, Iran. Jundishapur Journal of Chronic Disease Care 4(1): e26621

Mraihi R, Harizi R, Mraihi T, Bouzidi MT (2015) Urban air pollution and urban daily mobility in large Tunisia's cities. Renew Sust Energ Rev 43:315-320

Naimabadi A, Ghadiri A, Idani E, Babaei AA, Alavi N, Shirmardi M et al. (2016) Chemical composition of PM 10 and its in vitro toxicological impacts on lung cells during the Middle Eastern Dust (MED) storms in Ahvaz, Iran. Environ Pollut 211:316-24
Neisi A, Goudarzi G, Akbar Babaei A, Vosoughi M, Hashemzadeh H, Naimabadi A et al. (2016) Study of heavy metal levels in indoor dust and their health risk assessment in children of Ahvaz city, Iran. Toxin Reviews 35:16-23

Nelson SD, Malone D, Lafleur J (2015) Calculating the baseline incidence in patients without risk factors: a strategy for economic evaluation. PharmacoEconomics 33(39):887-892

Norval M, Lucas R, Cullen A, De Gruijl F, Longstreth J, Takizawa Y, Van Der Leun J (2011) The human health effects of ozone depletion and interactions with climate change. Photochemical \& Photobiological Sciences 10:199-225

PAGE JP (2003) Health effects of ozone. JAMA 290(14):1944

Peng RD, Butz AM, Hackstadt AJ, Williams D, Diette GB, Breysse PN, Matsui EC (2015) Estimating the health benefit of reducing indoor air pollution in a randomized environmental intervention. Journal of the Royal Statistical Society: Series A (Statistics in Society) 178: 425-443

Peters A, Skorkovsky J, Kotesovec F, Brynda J, Spix C, Wichmann HE, Heinrich J (2000) Associations between mortality and air pollution in Central Europe. Environ Health Perspect 108:283

Pope CA et al. (2002) Lung cancer and cardiovascular disease mortality associated with ambient air pollution and cigarette smoke: shape of the exposure-response relationships. Environ Health Perspect 119: 1616

Pride KR et al. (2015) Association of short-term exposure to ground-level ozone and respiratory outpatient clinic visits in a rural locationSublette County, Wyoming, 2008-2011. Environ Res 137:1-7

Raaschou-Nielsen O et al. (2013) Air pollution and lung cancer incidence in 17 European cohorts: prospective analyses from the European study of cohorts for air pollution effects (ESCAPE). The lancet oncology 14:813-822

Soleimani Z, Goudarzi G, Sorooshian A, Marzouni MB, Maleki H (2016) Impact of Middle Eastern dust storms on indoor and outdoor composition of bioaerosol. Atmos Environ 138:135-43

Sunyer J et al. (2003) The association of daily sulfur dioxide air pollution levels with hospital admissions for cardiovascular diseases in Europe (the Aphea-II study). Eur Heart J 24:752-760

Taghavirad S, Davar H, Mohammadi MJ (2014) The a study on concentration of BETX vapors during winter in the department of ports and shipping located in one of the southern cities of Iran. Inte J Cur Life Sci 4(9):5416-5420

Woerman AL (2013) Air pollution \& cardiovascular disease. Dissertation, the George Washington University

Wong T, Tam W, Yu T, Wong A (2002) Associations between daily mortalities from respiratory and cardiovascular diseases and air pollution in Hong Kong, China. Occup Environ Med 59:30-35

Wu Y, Zhao F, Qian X, Xu G, He T, Shen Y, Cai Y (2015) Relationship between sulfur dioxide pollution and upper respiratory outpatients in Jiangbei, Ningbo. Wei sheng yan jiu = Journal of hygiene research 44:565-569

Zallaghi E, Goudarzi G, Geravandi S, Mohammadi MJ (2014a) Epidemiological indexes attributed to particulates with less than 10 micrometers in the air of Ahvaz City during 2010 to 2013. Health Scope 3(4):e22276

Zallaghi E, Goudarzi G, Haddad MN, Moosavian SM, Mohammadi MJ (2014b) Assessing theEffects of nitrogen dioxide in urban air on health of west and southwest cities of Iran. Jundishapur Journal of Health Sciences 6(4):e23469

Zallaghi E, Geravandi S, Nourzadeh Haddad M, Goudarzi G, Valipour L, Salmanzadeh S, et al. (2015) Estimation of health effects attributed to nitrogen dioxide exposure using the AirQ model in Tabriz City, Iran. Health Scope 4(4):e30164

Geravandi S, Goudarzi G, Soltani F, Salmanzadeh S, Ghomeishi A, Zalaghi E, et al (2016) The cardiovascular and respiratory deaths attributed to sulfur dioxide in Kermanshah. Journal of Kermanshah University of Medical Sciences 26;19(6):319-26 